\title{
A FAMÍLIA BIGNONIACEAE NA APA DE MARICÁ, RIO DE JANEIRO, BRASIL
}

\author{
Cecilia Maria Rizzini ${ }^{1}$ \\ Fernando Vieira Agarez \\ Luis Henrique C. de Andrade ${ }_{3}^{2}$ \\ Andrea P. de Azevedo
}

Recebido em 22/8/96. Aceito em 3/11/97

\begin{abstract}
RESUMO - (A familia Bignoniaceae na APA de Maricá, Rio de Janeiro, Brasil). São estudadas as espécies da família Bignoniaceae que ocorrem na Restinga de Maricá, cuja flora se encontra ameaçada devido a diversas interferências que vêm alterando sua composição florística e vegetacional. A família está representada nesta área por sete gêneros e onze espécies, das quais seis são ocorrências novas para o local. O trabalho inclui a descrição da área de estudo em seus distintos gradientes, chaves analiticas para gêneros e espécies, descrições resumidas para as espécies, denominação popular, distribuição geográfica, material examinado e observações taxonômicas e de campo.
\end{abstract}

Palavras-chave: Bignoniaceae, Restinga de Maricá, florística

\begin{abstract}
The family Bignoniaceae of Maricá APA, Rio de Janeiro, Brazil). The species of Bignoniaceae which occur at Restinga de Maricá were studied. These taxa are threatened with extinction due to disturbances that are changing the floristic composition and vegetation of the area. The family is represented by seven genera and eleven species, six of which are new to the area. The different gradients of the studied area are described, analytic keys to the genera and species are included as well as popular nomenclature, geographic distribution, examined material and taxonomic and field observations.
\end{abstract}

Key words: Bignoniaceae, Restinga de Maricá, floristic

\section{Introdução}

Considerando que grande parte do litoral brasileiro possui em sua conformação áreas de grande relevância econômica, principalmente por seu potencial turístico, faz-se necessário ações racionais objetivando seu estudo e conservação através do

\footnotetext{
Departamento de Botânica, Instituto de Biologia, Universidade Federal do Rio de Janeiro, Av. Trompowsky s.n., Ilha do Fundão, Rio de Janeiro, CEP 21.044-021, RJ, Brasil

, Bolsa de Iniciação Cientifica do $\mathrm{CNPq}$

Estagiário
} 
inventário da flora, considerado básico e prévio para atividades de manejo e recuperação de áreas alteradas.

A Restinga de Maricá integra uma Área de Proteção Ambiental (APA) ameaçada de extinção pela ocupação humana com o avanço da construção civil, além de diversas outras interferências que vêm alterando significativamente sua composição florística e a estrutura da vegetação, como a retirada de areia das dunas, a coleta de mudas para a comercialização, queimadas, cortes sistemáticos de espécimes para a obtenção de lenha etc. Desta maneira, torna-se imperativo que se tenha um conhecimento pleno de sua flora através de estudos taxonômicos e ecológicos, assim como se intensifiquem as coletas científicas para a inclusão em herbários reconhecidos.

A fitofisionomia da restinga de Maricá é particularmente interessante, pois a disposição espacial dos seus elementos florísticos em forma de moitas circulares e com grandes espaços abertos e desnudos, raramente é observado em outras restingas brasileiras. Por outro lado, o crescimento das moitas e a formação de novas moitas pela propagação vegetativa de inúmeras espécies, sugere que a restinga está em franca progressão.

Este trabalho representa uma continuação de estudos anteriores, onde foram analisadas outras famílias botânicas representativas da flora local (Rizzini et al. 1990; Moreira \& Rizzini 1995). Tem como objetivo principal a investigação sistemática e minuciosa da composição florística dentro de gradientes com aspectos florísticos e vegetacionais distintos.

\section{Material e métodos}

A área estudada engloba a Área de Proteção Ambiental do Município de Maricá, Estado do Rio de Janeiro, distante cerca de $30 \mathrm{~km}$ do Município do Rio de Janeiro.

Foram realizadas excursões periódicas para a coleta de espécimes, documentário e observação in loco do comportamento das mesmas dentro das comunidades em que ocorrem. O material foi depositado no Herbário do Departamento de Botânica do Instituto de Biologia da UFRJ (RFA). Foram consultados, além do herbário acima referido, os Herbários do Museu Nacional (R) e do Jardim Botânico do Rio de Janeiro (RB).

O estudo taxonômico das espécies inclui chave para gêneros e espécies, quando necessário; citação das espécies com as respectivas obras originais; nomes vulgares bem conhecidos; descrições resumidas das plantas; distribuição geográfica e demais observações inerentes à ecologia das espécies.

A área de estudo foi dividida em gradientes distintos pelo seu aspecto fitofisionômico e florístico (Rizzini et al. 1990), a saber (Fig 1):

1. Zacaria: próxima à comunidade pesqueira de Zacaria, que corresponde a grande área desmatada, onde o solo é recoberto, basicamente, por gramíneas e algumas moitas baixas de Cactaceae, Bromeliaceae e Myrtaceae. São também comuns brotações novas de Sapotaceae, Lauraceae, Apocynaceae, assim como inúmeras plantas introduzidas. A pecuária, embora ocorrendo em pequena escala, contribui para a maior degradação desta área. As duas espécies de Bignoniaceae encontradas nesta área são 


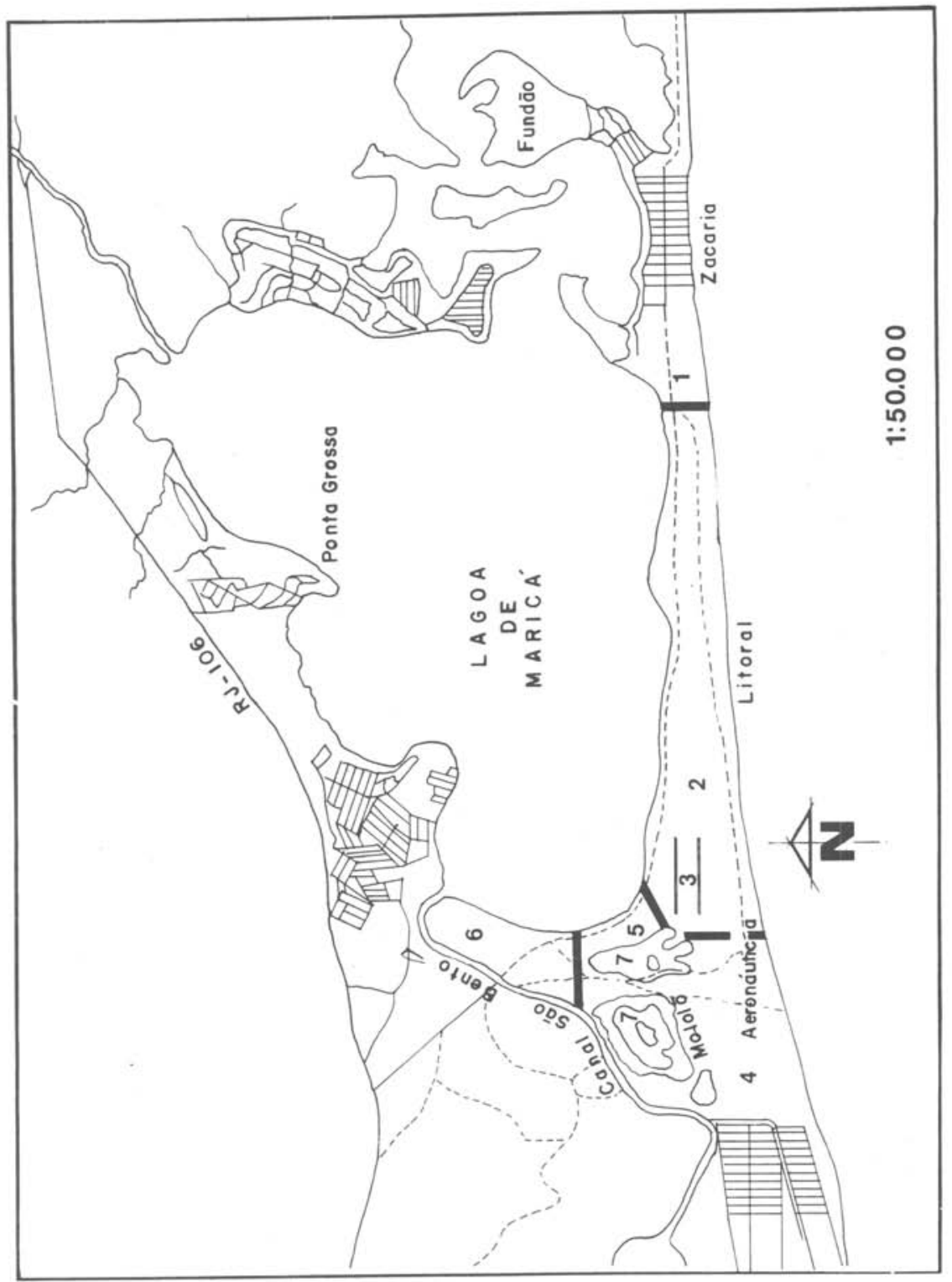

Figura 1. Áreas onde foram realizados os estudos de campo. (1) Zacaria; (2) Mar-Lagoa; (3) Alagado; (4) Mar-Morro do Mololô; (5) Lagoa-Morro do Mololô; (6) Lagoa-Canal de São Bento e (7) Morro do Mololô. 
freqüentes em associações secundárias de mata de encosta, além de serem reconhecidamente ornamentais (Sandwith \& Hunt 1974): Tabebuia chrysotricha e Pyrostegia venusta.

2. Mar-lagoa: onde se localizam os dois cordões arenosos, sendo a duna secundária próxima ao mar e a primária, próxima à lagoa. No primeiro predomina vegetação herbácea subarbustiva cortada por estrada litorânea. No segundo, as plantas são em geral arbustivas e estão agrupadas em moitas esparsas de tamanho variável, que permitem a livre circulação entre elas. Neste gradiente foram coligidas três espécies: Tabebuia chrysotricha e Anemopaegma prostratum, em indivíduos isolados pouco freqüentes, e Lundia cordata, esta em abundância.

3. Alagado (brejo): localizado entre os dois cordões arenosos do gradiente Marlagoa. Tabebuia cassinoides, espécie típica de áreas alagadas, é aqui encontrada numa alta densidade de indivíduos, porém em área restrita.

4. Mar-Morro do Mololô: inicialmente é representada por uma vegetação subarbustiva fechada, sem possibilidade de livre circulação. À medida que se afasta do mar e se aproxima do Mololô, a vegetação torna-se gradativamente mais alta, até atingir o porte arbóreo, formando mata alta, com dossel aproximado de $10 \mathrm{~m}$ de altura, onde a luz praticamente não penetra e a circulação é relativamente fácil. No subbosque são encontradas espécies de Bromeliaceae, Orchidaceae, Piperaceae, Cactaceae, Bignoniaceae, Gesneriaceae, Commelinaceae, Iridaceae, entre outras. Neste gradiente verifica-se a presença de cinco táxons da família em estudo: Jacaranda tomentosa, Pyrostegia venusta, Adenocalymma marginatum, Arrabidaea agnus-castus e Lundia virginalis var. nitidula, sendo os dois últimos raros na região e verificados somente neste gradiente

5. Lagoa-Morro do Mololô: inicialmente a vegetação de restinga apresenta-se disposta em moitas de diferentes tamanhos; gradativamente, as moitas vão se agrupando e a vegetação passa a ser arbórea e de fácil circulação. Esta fisionomia aproxima-se da base do morro, onde se inicia a transição entre a restinga (solo arenoso) e a vegetação secundária do morro (solo argiloso). Aqui encontra-se com grande freqüência Pyrostegia venusta e Arrabidaea conjugata.

6. Lagoa-Canal de São Bento: faixa de restinga bastante alterada pela ação antrópica. Junto à lagoa podem ser observados remanescentes de restinga arbórea, com árvores de $10-12 \mathrm{~m}$ de altura. No restante, a vegetação se dispõe em moitas. É comum a presença de plantas exóticas e/ou cultivadas. A única espécie de Bignoniaceae encontrada foi Jacaranda tomentosa.

7. Morro do Mololô: apresenta-se em algumas partes completamente desmatado e recoberto por vegetação graminóide. No mais, a vegetação é de capoeira fechada, com inúmeras lianas e com alguns exemplares arbóreos remanescentes. A família Bignoniaceae está aqui representada por cinco espécies: Jacaranda tomentosa, Tabebuia chrysotricha, Anemopaegma prostratum, Arrabidaea conjugata e Lundia cordata. 


\section{Resultados e discussão}

A família Bignoniaceae está representada na área de estudo por sete gêneros e 11 espécies, sendo o gênero Arrabidaea o mais representativo com três espécies, seguido de Tabebuia e Lundia com duas. Das espécies levantadas, mais da metade são citações novas para a região. Estes dados foram obtidos através de pesquisas bibliográficas (Figueiredo 1950; Rizzini 1979; Araújo \& Henriques 1984; Silva \& Somner 1984, entre outros), de consultas a herbários e de excursões periódicas. Já indicadas na literatura e/ou registradas em Herbários, tem-se: Adenocalymma marginatum (Cham.) DC., Arrabidaea conjugata (Vell.) Mart., Lundia cordata DC., Jacaranda tomentosa R. Br. e Tabebuia chrysotricha (Mart. ex DC.) Standl.

Este estudo permitiu ampliar as listagens existentes sobre a flora de Maricá com o registro de seis novas ocorrências: Arrabidaea agnus-castus DC., A. subincana DC., Lundia virginalis DC var. nitidula (DC.) A. Gentry, Pyrostegia venusta Miers, Anemopaegma prostratum DC. e Tabebuia. cassinoides (Lam.) DC.

Chave para os gêneros

1. Árvores ou arbustos

2. Folhas bipinadas, estaminódio maior que os estames 4. Jacaranda

2. Folhas simples ou compostas digitadas, estaminódio menor que os estames . 7. Tabebuia

1. Trepadeiras

3. Gavinhas trifidas 6. Pyrostegia

3. Gavinhas simples

4. Corola branco-amarelada a fortemente amarela

5. Cálice com glândulas disciformes visíveis a olho nu.1. Adenocalymma

5. Cálice com glândulas punctiformes visíveis apenas sob lente

4. Corola roxa a púrpura

2. Anemopaegma

6. Corola com 1,0-3,0 cm compr., anteras glabras 3. Arrabidaea

6. Corola de 3,0 a 6,0 cm compr., anteras pilosas 5. Lundia

\section{Adenocalymma Mart.}

Adenocalymma marginatum (Cham.) DC., Prod. 9: 200. 1845.

Trepadeira de ramos glabros. Folhas trifolioladas ou bifolioladas terminando em gavinha simples; folíolos 4,0-8,0 cm compr., 3,5-4,5cm larg., elípticos a oblongos, ápice acuminado. Inflorescências em racemos terminais, densamente pilosas. Flores com bractéolas pequenas de até $1,0 \mathrm{~mm}$, com glândulas escuras; cálice campanulado, truncado, denticulado no bordo e marcado com glândulas disciformes escuras, até $1,0 \mathrm{~cm}$ compr.; corola amarela, campanulada, pubescente na face externa, papilosopubérula internamente, até $5,5 \mathrm{~cm}$ compr.; anteras com tecas divaricadas. Frutos não observados. 
Nomes populares: feijão-grande (Correa 1952) e cipó-de-vaqueiro (Sandwith \& Hunt 1974).

Distribuição geográfica: Brasil - desde a Bahia até Rio Grande do Sul; Paraguai, Uruguai e parte da Argentina (Sandwith \& Hunt 1974).

Material examinado: BRASIL. Rio de Janeiro: Maricá, 28/XI/1988, fl., Agarez 33 \& Rizzini 467 (RFA).

Observações: observada no gradiente 4 .

2. Anemopaegma Mart.

Anemopaegma prostratum DC., Prod. 9: 189. 1845.

Trepadeira com ramos glabros. Folhas bifolioladas terminando em gavinha simples; folíolos com até $8,0 \mathrm{~cm}$ compr., $3,5 \mathrm{~cm}$ larg., oblongo-lanceolados, margem revoluta, glandular punctados. Inflorescências em racemos ou tirso, paucifloras. Flores com bractéolas de até $1,0 \mathrm{~mm}$; cálice largamente campanulado, truncado, glabro, glandular, ca. $0,8 \mathrm{~cm}$ compr.; corola com tubo palidamente amarelo e lacínias brancas, campanulado-afunilada, glabra, ca. $6,0 \mathrm{~cm}$ compr. Frutos não observados.

Nome popular: pente-de-macaco-liso (Sandwith \& Hunt 1974).

Distribuição geográfica: Brasil - do Estado do Espírito Santo e Minas Gerais até Rio Grande do Sul (Sandwith \& Hunt 1974).

Material examinado: BRASIL. Rio de Janeiro: Maricá, 12/XII/1988, fl., Agarez 39 \& Rizzini 454 (RFA); 10/X/1988, fl., Pereira s.n. RFA n 22250); 30/XI/1988, fl. botão, Azeredo $34 \mathrm{~A}$ et al. (RFA).

Observações: registrada pela primeira vez na região; ocorre nos gradientes 2 e 7 .

3. Arrabidaea DC.

Chave para as espécies

1. Antera com tecas paralelas, corola ca. $1,0 \mathrm{~cm}$ compr. 3.1. A. agnus-castus

1. Antera com tecas divaricadas, corola entre $1,5-3,0 \mathrm{~cm}$ compr.

2. Folíolos glabros, corola ca. $3,0 \mathrm{~cm}$ compr. 3.2. A. conjugata

2. Folíolos pilosos, corola ca. $1,5 \mathrm{~cm}$ compr. 3.3. A. subincana

3.1.Arrabidaea agnus-castus DC., Prod. 9: 183.1845.

Trepadeira com folhas trifolioladas ou bifolioladas terminando em gavinha simples; folíolos ovado-oblongos, com até $5,5 \mathrm{~cm}$ compr., $3,0 \mathrm{~cm}$ larg., densamente pubérulos na face inferior. Inflorescências paniculadas, amplas. Flores com cálice cupular, extremamente piloso, ca. $0,3 \mathrm{~cm}$ compr., com dentes pequenos; corola roxa, mais escura na base, totalmente tomentosa, ca. 1,0 cm compr.; estames com anteras de tecas paralelas, filetes pilosos na base. Frutos não observados. 
Nomes populares: cipó-rego, cipó-camarão (Gomes 1957).

Distribuição geográfica: Brasil - Alagoas até São Paulo e Minas Gerais (Correa 1931). Material examinado: BRASIl. Rio de Janeiro: Maricá, 06/XII/1988, fl., Agarez 37 \& Rizzini 457 (RFA).

Observações: espécie pouco freqüente, encontrada somente no gradiente 4. Ocorrência nova.

3.2. Arrabidaea conjugata (Vell.) Mart., in Mart. Fl. Bras. 8(2):34. 1897.

Bignonia conjugata Vell.

Trepadeira com folhas trifolioladas ou bifolioladas, terminando em gavinha simples; folíolos glabros, coriáceos, oblongos a lanceolado-ovados, até $9,0 \mathrm{~cm}$ compr., $5,5 \mathrm{~cm}$ larg. Inflorescências paniculadas, multifloras. Flores com cálice pubérulo, ca. $1,0 \mathrm{~cm}$ compr., com 5 dentes pequenos; corola arroxeada ou vinácea, ca. $3,0 \mathrm{~cm}$ compr.; estames com anteras divaricadas. Cápsula linear, alongada e achatada, 10,5-35,0 cm compr., com nervura mediana.

Nome popular: arrabidea-rosa (sugerido por Correa 1926)

Distribuição geográfica: Brasil - Rio de Janeiro, São Paulo, Brasília, Mato Grosso, Pará, Amazonas (Gomes 1957).

Material examinado: BRASIL. Rio de Janeiro: Maricá, 10/XI/1975, fl., Occhioni 6878 (RFA); 15/IX/1986, fl. fr., Bove 24 (RFA); 16/V/1988, fl. fr., Agarez 17 \& Rizzini 461 (RFA); 28/XI/1988, fl., Agarez 35 \& Rizzini 469 (RFA); 03/X/1988, fl., Pereira s.n. (RFA n 22248); 16/VIII/1988, fl. fr , Barros 376.(RFA); 03/III/1988, Ormond 253 et al. (R).

Observações: registrada nos gradientes 5 e 7 , onde é muito freqüente.

3.3. Arrabidaea subincana DC. in Mart. Fl. Bras. 8(2): 34. 1896.

Trepadeira com folhas trifolioladas ou bifolioladas, terminando em gavinha simples; folíolos pilosos, ovados a lanceolado-ovados, até $6,0 \mathrm{~cm}$ compr., $3,7 \mathrm{~cm}$ larg. Inflorescências paniculadas, multifloras Flores com cálice cupular, piloso, bordo liso, com até $0,5 \mathrm{~cm}$ compr.; corola roxa, campanulada a infundibuliforme, tomentosa externamente (assim como na fauce e na inserção dos estames), com cerca de $1,5 \mathrm{~cm}$ compr.; estames com anteras divaricadas, glabros. Frutos não observados.

Nome popular: desconhecido

Distribuição geográfica: Brasil - Rio de Janeiro e Bahia (Bureau \& Schumann 1896). Material examinado: BRASII. Rio de Janeiro: Maricá, 27/XI/1988, fl., Pereira s.n. (RFA n ${ }^{\circ} 22252$ ). 
Observações: espécie rara na APA de Maricá. Ocorrência nova.

\section{Jacaranda Juss.}

Jacaranda tomentosa R. Br., Curtis Bot. Mag. t. 2327. 1811.

Arbusto até 2,0m alt. Folhas bipinadas discolores; folíolos pubescentes na face superior e tomentosos na inferior, lanceolados, largamente-lanceolados ou lanceoladoovados. Inflorescências em dicásios. Flores com cálice 5 -dentado, piloso, ca. $0,8 \mathrm{~cm}$ compr.; corola roxo-escuro, pilosa, ca. $5,0 \mathrm{~cm}$ compr. Cápsula arredondada, achatada, bordos lisos, ca. $6,0 \mathrm{~cm}$ compr.

Nome popular: caroba-miúda (Correa 1931)

Distribuição geográfica: Brasil - Rio de Janeiro (Correa ibid.)

Material examinado: BRASIL. Rio de Janeiro: Maricá, 03/X/1988, fl., Agarez 24 \& Rizzini 453 (RFA); 10/X/1988, fl., Pereira s.n.(RFA n ${ }^{\circ} 22253$ ); 12/XII/1988, fl., Agarez 40 \& Rizzini 464 (RFA); 22/X/1962, fl., Wariz 19 (RFA); 03/X/1988, fl., Pereira s.n (RFA n ${ }^{\circ}$ 22257); 9/V/1988, fl., Agarez 08 \& Rizzini 468 (RFA); 16/V/ 1988, fr., Agarez 15 \& Rizzini 458 (RFA); 28/XI/1988, fl. fr., Agarez 34 \& Rizzini 455 (RFA); 26/XI/1969, fl., Mattos Fo. 502 \& Rizzini .s.n. (RB).

Observações: espécie freqüente nos gradientes 4, 6 e 7, ocorrendo isoladamente.

\section{Lundia DC.}

Chave para as espécies

1. Trepadeira de ramos e foliolos pubescentes; flores inteiramente purpúreas; cálice pubescente, lobos irregulares 5.1. L. cordata

1. Trepadeira de ramos e folíolos glabros; flores bicolores; cálice glabro, lobos truncados 5.2. L. virginalis var. nitidula

\subsection{Lundia cordata DC., Prod. 9: 180.1845.}

Trepadeira de ramos pubescentes; folhas trifolioladas ou bifolioladas terminando em gavinha simples; folíolos pubescentes, principalmente nas nervuras e margem, cordado-ovados com ápice obtuso a acuminado, 3,5-8,0 cm compr., 2,0-5,0cm larg. Inflorescências em cimeiras axilares ou terminais. Flores com cálice campanulado, irregularmente lobado, pubescente, ca. $0,8 \mathrm{~m}$ compr.; corola púrpura, densamente tomentosa na face externa, ca. $6,0 \mathrm{~cm}$ compr.; estames levemente exsertos, anteras pilosas. Frutos não observados.

Nome popular: desconhecido

Distribuição geográfica: Brasil - Pernambuco, Bahia, Goiás, Espírito Santo, Rio de Janeiro, São Paulo (Bureau \& Schumann 1897). 
Material examinado: BRASIL. Rio de Janeiro: Maricá, 09/V/1988, fl., Agarez 07 \& Rizzini 459 (RFA); 15/IX/1986, fl. fr., Bove 25 (RFA); 04/VII/1988, fl., Pereira s.n. (RFA 22247); 10/X/1988, fl., Pereira s.n. (RFA n ${ }^{\circ} 22249$ ); 10/X/1988, fl., Pereira s.n. (RFA 22254); 16/IV/1975, fl., Araújo 663 \& Peixoto s.n. (RB); 21/IV/1975, fl., Araújo s.n. \& Peixoto s.n. (RB 169695); 05/I/1984, fl., Silva 580 et. al. (R); III/1943, Vidal s.n. (R 39283).

Observações: espécie muito freqüente no gradiente 2, ocorrendo também no 7.

5.2. Lundia virginalis DC. var. nitidula (DC.) A. Gentry, Ann. Missouri Bot. Gard. 64(2): 135. 1978.

L. nitidula DC., Prod. 9: 181. 1845.

- Trepadeira de ramos glabros; folhas trifolioladas ou bifolioladas terminando em gavinha simples; folíolos glabros, ovados a ovado-oblongos, ápice acuminado, base arredondada, 3,5-5,5cm compr., 1,5-2,5cm larg. Inflorescências em cimeiras laterais ou terminais. Flores com cálice truncado, glabro, ca. $0,6 \mathrm{~cm}$ compr.; corola alvo-rosada externamente, roxa internamente, densamente tomentosa na face externa, $3,0-4,5 \mathrm{~cm}$ compr.; estames inclusos, anteras pilosas. Frutos não observados.

Nome popular: cipó-de-alho (Sandwith \& Hunt 1974).

Distribuição geográfica: Brasil - Brasília, Rio de Janeiro, São Paulo, Minas Gerais, Espírito Santo, Bahia e Pernambuco (Gomes 1957 - L. nitidula).

Material examinado: BRASIL. Rio de Janeiro: Maricá, 06/XII/1988, fl., Agarez 38 \& Rizzini 463 (RFA).

Observações: encontrado somente um indivíduo no gradiente 4, em farta floração. Ocorrência nova.

\section{Pyrostegia Presl.}

Pyrostegia venusta (Ker Gawl.) Miers, Proc. Roy. Hort. Soc. London 3: 188. 1863.

P. ignea (Vell.) K.B. Presl., Bot. Benerk. 93. 1843.

Bignonia venusta Ker Gawl.

Bignonia ignea Vell.

Trepadeira com ramos glabros e râmulos pilosos. Folhas trifolioladas ou bifolioladas terminando em gavinha trífida; folíolos oblongo-lanceolados a oblongoovados, $3,0-7,0 \mathrm{~cm}$ compr., $1,5-3,5 \mathrm{~cm}$ larg., ápice obtuso a acuminado, glabros com glândulas espalhadas por toda a face inferior, sendo que na base as glândulas são maiores. Inflorescências em panículas corimbosas. Flores com cálice campanulado, com pequenos dentes e bordos ciliados, externamente pouco pilosos ou glabros, ca. $0,5 \mathrm{~cm}$ compr.; corola de cor laranja a abóbora, glabra externamente, até $6,5 \mathrm{~cm}$ compr.; estames de anteras paralelas e exsertas. Frutos não observados. 
Nome popular: cipó-de-São-João (Correa 1931).

Distribuição geográfica: Brasil - todos os Estados; Paraguai, Bolívia e parte da Argentina (Sandwith \& Hunt 1974).

Material examinado: BRASIL. Rio de Janeiro: Maricá, 04/X/1991, fl., Chauvet 73 et al. (RFA); 04/VI/1988; fl., Agarez 18 \& Rizzini 466 (RFA); 10/X/1988, fl., Pereira s.n. (RFA n 22251$) ; 20 / \mathrm{VI} / 1988$, fl., Pereira s.n. (RFA n $\left.{ }^{\circ} 22255\right)$.

Observações: cultivada em todas as regiões tropicais do mundo (Gentry 1982). Encontrada nos gradientes 1, 4 e 5, formando densas populações que se destacam pela coloração de suas flores. Registrada pela primeira vez na APA de Maricá.

\section{Tabebuia Gomez}

Chave para as espécies:

1. Folhas simples, cálice glandular; corola glabra externamente, fauce amarela e lacínias brancas 7.1. T. cassinoides

1. Folhas digitadas, cálice sem glândulas, corola totalmente pilosa e inteiramente amarela

7.2. T. chrysotricha

7.1. Tabebuia cassinoides (Lam.) DC., Prod 9: 213.1845.

Bignonia cassinoides Lam.

Árvore até $5 \mathrm{~m}$ alt.; tronco com raizes aéreas. Folhas simples, pecíolos ca. $2,0 \mathrm{~cm}$ compr., coriáceas, pubescentes na face inferior, oblongo-lanceoladas ou obovadolanceoladas, com glândulas, $6,0-21,0 \mathrm{~cm}$ compr., 2,0-7,0 cm larg. (ramos vegetativos), 4,5-15,0 cm compr., 2,0-4,0 cm larg. (ramos florais). Inflorescências cimosas, em ramos com folhas. Flores com cálice glandular, ca. $2,0 \mathrm{~cm}$ compr.; corola com fauce amarela e lacínias brancas, glabra externamente, $7,0 \mathrm{~cm}$ compr. Cápsulas lineares e cilíndricas, ca. $7,5 \mathrm{~cm}$ compr. (imaturas), valvas percorridas por nervura mediana.

Nomes populares: caixeta, corticeira, pau-caixeta, pau-de-tamanco, tabebuia-do-brejo (Correa 1926).

Distribuição geográfica: Brasil - Espírito Santo, Rio de Janeiro, São Paulo e Paraná (Gentry 1992).

Material examinado: BRASIL. Rio de Janeiro: Maricá, 21/XI/198\&, fl. fr., Agarez 30 \& Rizzini 460 (RFA).

Observações: espécie típica de áreas alagadas (gradiente 3), onde ocorre em abundância. Citada pela primeira vez para a região em estudo.

7.2.Tabebuia chrysotricha (Mart. ex DC.) Standl., Publ. Field. Mus. Nat. Hist. Bot. Ser. 11: 176. 1936. 
Tecoma chrysotricha Mart. ex DC., Prod. 9: 216. 1845.

Arvoreta ca. $3 \mathrm{~m}$ alt. Folhas digitadas com 5 folíolos ( 2 caem com facilidade); folíolos obovado-orbiculares, densamente cobertos com pêlos ramificados, ca. $4,0 \mathrm{~cm}$ compr., $3 \mathrm{~cm}$ larg. Inflorescências sub-umbeladas. Flores com cálice amarelo-áureo, campanulado, tomentoso, 5-dentado, ca. 1,5cm compr.; corola amarela, campanuladoafunilada, pilosa na parte superior do tubo (pêlos em linhas verticais), ca. $5,5 \mathrm{~cm}$ compr. Frutos não observados.

Nomes populares: ipê-do-morro, ipê-amarelo, aipê, ipê-tabaco, pau-d'arco-amarelo, ipê (Correa 1969).

Distribuição geográfica: Brasil - Espírito Santo, Rio de Janeiro, Paraná (Correa ibid.); Pernambuco, Paraná, Santa Catarina (Sandwith \& Hunt 1974); Bahia, Minas Gerais, Paraíba, Rio Grande do Sul, Argentina (Gentry 1992).

Material examinado: BRASIl. Rio de Janeiro: Maricá, 09/V/1988, fl., Agarez 06 \& Rizzini 465 (RFA); 06/XII/1988, fl., Agarez 36 \& Rizzini 462 (RFA); 04/X/1991, fl., Chauvet 72 (RFA); 16/IV/1975, fl., Araújo 672 \& Peixoto s.n. (RB); 27/X/1988, fl., Marquete 144 et al. (RB); 27/IX/1988, fl., Pinheiro 377 et al. (R).

Observações: são encontrados nos gradientes 1, 2 e 7 indivíduos isolados.

\section{Referências bibliográficas}

Araújo, D.S.D. \& Henriques, R.P.B. 1984. Análise florística das restingas do Estado do Rio de Janeiro. Pp. 159193. In: L.D. Lacerda; D.S.D. de Araujo; R. Cerqueira \& B. Turcq (Eds.), Restingas: Origem, Estrutura, Processos. Niterói. CEUFF.

Bureau, E. \& Schumann, K. 1896-7. Bignoniaceae. In C.F.P. von Martius et al., Flora Brasiliensis. München, Wien, Leipzig, vol. 8(2): 01-452.

Correa, M.P. 1926-69. Dicionário das plantas úteis do Brasil e das exóticas cultivadas. Rio de Janeiro. Ministério da Agricultura, Indústria e Comércio, vols. 1 a 4.

Figueiredo, E.R. 1950. A flora e a fauna de Maricá. Anuário Geográfico do Estado do Rio de Janeiro 3: 13 48.

Gentry, A.H. 1982. Bignoniaeae. In Flora de Veracruz. Veracruz: Instituto Nacional de Investigação sobre Recursos Bióticos. fasc. 24:169.

Gentry, A.H. 1992. Bignoniaceae (Tribe Tecomeae). In Flora Neotropica. New York. Hafner Press, 25(2):163169.

Gomes, J.C. 1957. Flora de Itatiaia I - Bignoniaceae. Rodriguésia 20(32): 111-127.

Moreira, B.A. \& Rizzini, C.M. 1995. As familias Loranthaceae e Viscaceae na AA de Maricá, Rio de Janeiro, Brasil. Acta Botanica Brasilica 11(1). 1-8

Rizzini, C. M.; Pereira, C.; Occhioni, E.M.L\& Agarez, F.V. 1990. Considerações sobre a ocorrência de Cactaceae na APA de Maricá, Rio de Janeiro, Brasil. Acta Botanica Brasilica 4(2): 171-182.

Rizzini, C.T. 1979. Tratado de Fitogeografia do Brasil - aspectos sociológicos e florísticos. São Paulo. HUCITEC e Universidade de São Paulo p. 224-242.

Sandwith, N.Y. \&.Hunt, D.R. 1974. Bignoniáceas. In R. Reitz (Ed.), Flora Ilustrada Catarinense. Santa Catarina.

Silva, J. G. da \&.Somner, G 1984. A vegetação de Restinga na Barra de Maricá, RJ. Pp. 217-225. In: L.D. Lacerda; D.S.D. de Araujo; R. Cerqueira \& B. Turcq (Eds.), Restingas: Origem, Estrutura, Processos. Niterói. CEUFF. 